ORIGINAL ARTICLE

\title{
AVALIAÇÃO BROMATOLÓGICA E DIGESTIBILIDADE “IN VITRO” DE RAÇÕES PARA BOVINOS FORMULADAS COM COPRODUTOS DA INDÚSTRIA DO MILHO E DO ÁCIDO CÍTRICO
}

\author{
Fernanda Heloisa Litz ${ }^{1 *}$, Evandro de Abreu Fernandes ${ }^{1}$, Cesar Calabria Pimenta ${ }^{1}$, \\ Naiara Simarro Fagundes ${ }^{2}$, Isabel Cristina Ferreira ${ }^{1}$, Mayara Fabiane Gonçalves ${ }^{1}$
}

\section{INTRODUÇÃO}

O aumento dos preços dos alimentos energéticos e proteicos para a alimentação animal refletem na elevação do custo de produção reduzindo a margem de lucro para os produtores. Os coprodutos das agroindústrias de alimentos nestas oportunidades passam a ter atenção especial, uma vez que normalmente apresentam baixo custo de aquisição (GOES et al., 2008).

No Brasil é produzido um volume muito grande de coprodutos agroindustriais oriundos do processamento de grãos destinados a produção de alimento industrializados. Alguns são restritos a determinadas regiões, enquanto outros são facilmente encontrados em todo país. Ainda hoje a utilização de muitos coprodutos na alimentação é limitada pelo pouco conhecimento das suas características nutricionais, seu valor econômico como ingrediente para a ração e falta de dados de desempenho de animais alimentados com estes alimentos (MENEGHETTI e DOMINGUES, 2008).

O resíduo industrial, depois de gerado, necessita de destino adequado, pois não pode ser acumulado indefinidamente (AQUARONE, 1990). Além de criar potenciais problemas ambientais, os resíduos representam perdas de matérias-primas e energia, exigindo investimentos significativos em tratamentos para controlar a poluição (TIMOFIECSYK e PAWLOWSKY, 2000). $A$ indústria de alimentos produz uma série de resíduos com alto valor de (re) utilização. Inúmeros estudos utilizando resíduos industriais do processamento de alimentos têm sido realizados com objetivo de aproveitamento destes. Com isso, minimiza-se o impacto ambiental destes tipos de indústrias na região onde estão situadas e ainda agrega-se valor aos produtos do mercado (PELIZER, PONTIERI, MORAES, 2007). Agregar valor a estes subprodutos é de interesse econômico, científico e tecnológico (FERRARI et al. 2004).

A avaliação do valor nutricional dos alimentos é a base para qualquer formulação de ração e, a cada dia, mais alimentos são estudados. Um dos quesitos necessários para a obtenção dessa informação é o estudo da digestibilidade, que possibilita estimar quais nutrientes estarão disponíveis para o animal, permitindo uma melhor associação entre ingredientes (WATANABE et al., 2010).

Existem vários coprodutos de possível utilização na alimentação dos animais ruminantes, entre eles têm-se o micélio, précoat e rafinate. O micélio é um coproduto intermediário da produção do acido cítrico destinado à indústria alimentícia, principalmente bebidas. $\mathrm{Na}$ pré- fase da produção, o fungo Aspergillus niger é colocado em incubadoras com substratos, como sabugo de milho, farelo de algodão, e água acidificada, para promover o seu crescimento. Posterior ao crescimento inicia-se a produção do ácido cítrico.

\footnotetext{
${ }^{*}$ Artigo recebido em: 09/09/2013

Aceito para publicação em: 16/01/2015

${ }^{1}$ Laboratório de Nutrição Animal, Faculdade de Medicina Veterinária, Universidade Federal de Uberlândia.

${ }^{2}$ Escola Superior de Agricultura "Luiz de Queiroz", EsalQ

fernandalitz@veterinaria.med.br

Rua Ceará s/n, Bloco 2D, Sala 36, Bairro Umuarama, Uberlândia, MG 38402-018, Brazil
} 
O fungo é destinado aos tanques de fermentação na presença dos substratos dextrose ou açúcar, minerais, antiespumantes, surfactantes e água filtrada em condições controladas de $\mathrm{pH}$, temperatura e umidade. Após a máxima conversão do açúcar em ácido cítrico, as condições de crescimento são inibidas, o fungo é inativado e ocorre a separação da biomassa do micélio do caldo fermentado. Essa biomassa que contém o fungo inativado, o veiculo de crescimento, os resíduos de açúcar e ácido cítrico passam por uma prensa que eleva o teor de matéria seca a $35 \%$.

Para produção do Rafinate, um solvente é adicionado no caldo fermentado para que ocorra a extração do ácido cítrico. $\mathrm{O}$ produto final desta extração, composto principalmente de açucares intermediários do processo de conversão do ácido cítrico, é denominado Rafinate. O Rafinate sofre evaporação para concentrar os constituintes.

O Precoat é o resíduo oriundo da etapa de filtração de xarope de glicose, após várias etapas para obtenção do amido do milho. Há, neste processo, uma purificação por uma camada filtrante, composta por minerais inertes de terra diatomácea, em filtros rotativos que deixam o xarope purificado. A camada filtrante é composta por extrato etéreo, proteína, minerais e traços do xarope que farão parte do Précoat.

Objetivou-se avaliar a composição bromatológica e o valor de digestibilidade in vitro de rações formuladas para bovinos com três coprodutos oriundos da indústria de processamento do milho e do ácido cítrico.

\section{MATERIAL E MÉTODOS}

O experimento foi realizado no Laboratório de Nutrição Animal da Universidade Federal de Uberlândia no período de Janeiro a Março de 2013, onde realizou-se a análise bromatológica dos ingredientes e coprodutos utilizados e a digestibilidade in vitro das dietas formuladas para bovinos.

As dietas foram formuladas e produzidas à base de coproduto do milho, farelo de glúten de milho 21 (FGM 21), farelo de glúten de milho úmido (FUGM) e bagaço de cana, constituindo a base de um experimento de ganho de peso de novilhas mestiças desenvolvido na Fazenda Experimental do Gloria da Universidade Federal de Uberlândia, sendo os tratamentos assim designados:
A - Dieta basal - Controle
M - Dieta com inclusão do coproduto Micélio
P - Dieta com inclusão do coproduto Precoat
$\mathrm{R}$ - Dieta com inclusão do coproduto Rafinate
As matérias primas antes da formulação das rações foram analisadas no Laboratório de Nutrição Animal da Universidade Federal de Uberlândia sendo determinados os teores de matéria seca (MS), proteína bruta (PB), extrato etéreo ( $E E)$, matéria mineral $(\mathrm{MM})$ de acordo com a metodologia do Compêndio Brasileiro de Alimentação Animal (BRASIL, 2009), de fibra detergente ácido (FDA) e fibra detergente neutro (FDN) (SILVA e QUEIROZ, 2002) e a digestibilidade in vitro (TILLEY e TERRY, 1963). Das rações experimentais foram determinadas as mesmas variáveis acima e a digestibilidade in vitro (TILLEY e TERRY, 1963). As amostras foram analisadas semanalmente por um período de cinco semanas. Os resultados estão apresentados na Tabela 1 .

O experimento foi realizado em delineamento em blocos casualizados (DBC), onde as dietas experimentais eram os tratamentos e os blocos foram as datas das amostras. 
Tabela 1. Análises bromatológicas e de digestibilidade in vitro das matérias primas

\begin{tabular}{cccccccc}
\hline Amostra & $\begin{array}{c}\text { MS } \\
\%\end{array}$ & $\begin{array}{c}\text { PB } \\
\%\end{array}$ & $\begin{array}{c}\text { EE } \\
\%\end{array}$ & $\begin{array}{c}\text { FDA } \\
\%\end{array}$ & $\begin{array}{c}\text { MM } \\
\%\end{array}$ & $\begin{array}{c}\text { FDN } \\
\%\end{array}$ & $\begin{array}{c}\text { Digestibilidade } \\
\text { MS \% }\end{array}$ \\
\hline Resíduo Milho & 91,45 & 11,1 & 3,44 & 6,3 & 4,98 & 19,17 & 82,93 \\
FGM 21 ** & 90,54 & 24,05 & 4,16 & 11,64 & 5,67 & 26,04 & 95,05 \\
Precoat & 72,94 & 5,59 & 2,06 & 2,14 & 64,54 & 6,52 & 52,93 \\
Rafinate & 74,58 & 8,77 & 1,52 & 0 & 3,49 & 0 & $X$ \\
FUGM ${ }^{*}$ & 39,71 & 24,55 & 3,46 & 17,56 & 5,49 & 41,21 & 78,55 \\
Micélio & 16,78 & 18,52 & 6,52 & 7,52 & 5,63 & 21,49 & 53,30 \\
Bagaço cana & 48,88 & 2,14 & 1,24 & 48,63 & 2,21 & 79,63 & 26,14 \\
\hline
\end{tabular}

*FUGM= Farelo Úmido de Glúten de Milho ** FGM 21= Farelo Gluten de Milho 21\% de proteína bruta

Tabela 2. Composição percentual de alimentos das dietas utilizadas

\begin{tabular}{|c|c|c|c|c|}
\hline \multirow{2}{*}{ Descrição } & Controle & Micélio & Precoat & Rafinate \\
\hline & \multicolumn{4}{|c|}{$\%$ da Matéria natural } \\
\hline Bagaço de cana & 22,60 & 21,50 & 22,50 & 20,41 \\
\hline FUGM * & 49,00 & 47,95 & 48,90 & 48,60 \\
\hline FGM 21 ** & 6,50 & 4,00 & 5,60 & 5,40 \\
\hline Milho Quebrado & 20,34 & 19,51 & 18,03 & 19,23 \\
\hline Micélio prensado & 0,00 & 5,50 & 0,00 & 0,00 \\
\hline Precoat & 0,00 & 0,00 & 3,40 & 0,00 \\
\hline Rafinate & 0,00 & 0,00 & 0,00 & 4,80 \\
\hline Núcleo Min/Vit ${ }_{1}$ & 1,56 & 1,54 & 1,57 & 1,56 \\
\hline Total & 100,00 & 100,00 & 100,00 & 100,00 \\
\hline \multicolumn{5}{|c|}{ Composição nutricional calculada com base na matéria seca (\% da MS) } \\
\hline MS & 61,88 & 62,42 & 62,60 & 62,13 \\
\hline PB & 15,84 & 15,70 & 15,67 & 15,77 \\
\hline NDT & 68,00 & 68,00 & 68,50 & 65,00 \\
\hline EE & 2,23 & 2,25 & 3,67 & 2,14 \\
\hline FDN & 41,60 & 42,57 & 41,64 & 40,10 \\
\hline CNF & 30,44 & 29,87 & 26,77 & 31,97 \\
\hline Amido & 21,16 & 20,67 & 18,10 & 20,21 \\
\hline K & 1,00 & 0,96 & 0,96 & 0,95 \\
\hline $\mathrm{Cl}$ & 0,22 & 0,21 & 0,21 & 0,21 \\
\hline $\mathrm{Na}$ & 0,16 & 0,16 & 0,16 & 0,21 \\
\hline$S$ & 0,34 & 0,37 & 0,36 & 0,33 \\
\hline $\mathrm{Mg}$ & 0,29 & 0,27 & 0,27 & 0,27 \\
\hline $\mathrm{Ca}$ & 0,94 & 0,93 & 0,94 & 0,93 \\
\hline $\mathrm{P}$ & 0,60 & 0,58 & 0,59 & 0,57 \\
\hline $\mathrm{Ca}: \mathrm{P}$ & 1,57 & 1,60 & 1,59 & 1,63 \\
\hline
\end{tabular}

${ }^{*}$ FUGM = Farelo Úmido de Glúten de Milho ** FGM 21 = Farelo Gluten de Milho $21 \%$ de proteína bruta ${ }^{1}$ Núcleo Min/Vit níveis nutricionais (por kg de produto) - Ca 32,28g; K xx,x; I 0,51mg; Zn 79,47mg; Se 0,40mg; Mn 43,45mg; Cu 14,97mg; Co 0,26mg; Vit A 2.966 Ul; Vit D3 741mg; Vit E 18,5 mg; Monensina Sódica 20\% 20,06mg 
Para a realização do ensaio da digestibilidade in vitro foram coletadas amostras de cada dieta num total de cinco amostras no período sendo submetidas à metodologia descrita por Tilley e Terry (1963). Utilizou-se uma vaca Holandesa, não gestante, não lactante, fistulada no rúmen como doadora de líquido ruminal.

A normalidade dos coprodutos foi verificada por meio do teste de ShapiroWilk. Os dados foram submetidos à análise de variâncias e as médias comparadas pelo teste de Tukey $5 \%$ por meio do PROC MIXED do SAS versão 9.3 (SAS Institute Inc., Cary, NC, USA).

\section{RESULTADOS E DISCUSSÃO}

$\mathrm{Na}$ Tabela 3 são demonstrados os resultados de digestibilidade das dietas experimentais, incluídas em suas formulações os coprodutos originados na indústria de processamento de milho e ácido cítrico.

Tabela 3. Digestibilidade da matéria seca (DMS\%), proteína bruta (DPB\%), extrato etéreo (DEE\%), matéria mineral (DMM\%), fibra detergente ácido (DFDA\%) e fibra detergente neutro (DFDN\%) de rações formuladas com coprodutos da indústria do milho e do ácido cítrico.

\begin{tabular}{ccccccc}
\hline & $\begin{array}{c}\text { DMS } \\
(\%)\end{array}$ & $\begin{array}{c}\text { DPB } \\
(\%)\end{array}$ & $\begin{array}{c}\text { DEE } \\
(\%)\end{array}$ & $\begin{array}{c}\text { DMM } \\
(\%)\end{array}$ & $\begin{array}{c}\text { DFDA } \\
(\%)\end{array}$ & $\begin{array}{c}\text { DFDN } \\
(\%)\end{array}$ \\
\hline Controle & $66,81 \mathrm{a}$ & $95,65 \mathrm{~b}$ & $87,67 \mathrm{a}$ & $83,20 \mathrm{~b}$ & $61,64 \mathrm{a}$ & $31,73 \mathrm{a}$ \\
Micelio & $65,45 \mathrm{a}$ & $96,36 \mathrm{a}$ & $73,52 \mathrm{~b}$ & $84,69 \mathrm{~b}$ & $57,51 \mathrm{~b}$ & $19,57 \mathrm{c}$ \\
Precoat & $63,73 \mathrm{~b}$ & $94,85 \mathrm{c}$ & $83,67 \mathrm{a}$ & $83,99 \mathrm{~b}$ & $52,93 \mathrm{c}$ & $25,32 \mathrm{~b}$ \\
Rafinate & $61,67 \mathrm{c}$ & $92,51 \mathrm{~d}$ & $88,29 \mathrm{a}$ & $89,30 \mathrm{a}$ & $53,82 \mathrm{c}$ & $19,91 \mathrm{c}$ \\
\hline CV $(\%)$ & 3,36 & 1,61 & 8,10 & 3,01 & 7,01 & 22,03 \\
P valor & $<0,0001$ & $<0,0001$ & $<0,0001$ & $<0,0001$ & $<0,0001$ & $<0,0001$ \\
\hline
\end{tabular}

Médias seguidas por letras diferentes na coluna diferem entre si pelo teste de Tukey $5 \%$ $(P<0,05)$.

Observa-se que a digestibilidade in vitro, um recurso de ensaio laboratorial frequentemente utilizado na avaliação de valor nutricional de alimentos para ruminantes, foi estatisticamente igual para a digestibilidade da matéria seca (DMS) da dieta controle e aquela produzida com a inclusão do coproduto micélio. A dieta produzida com a inclusão de precoat teve um valor de DMS intermediário, enquanto a inclusão do rafinate apresentou piores valores para digestibilidade. Este resultado de digestibilidade das dietas testadas neste experimento, no entanto, mostra-se muito compatível com os valores de digestibilidade in vitro para silagens - silo trincheira, silo superfície e silo bag - do farelo úmido de glúten de milho (FUGM) no terceiro dia de ensilado (GONÇALVES et al., 2012). A ingestão de matéria seca é importante, entre outros fatores, por influenciar o desempenho do animal, pois é 0 primeiro ponto determinante da ingestão de nutrientes necessários ao atendimento das exigências de mantença e de produção (NOLLER et al., 1996).

A digestibilidade da proteína bruta (DPB) foi maior $(96,36 \%)$ na dieta inclusão do micélio, sendo superior à ração controle $(95,65 \%)$. A dieta com a inclusão do rafinate apresentou o menor valor de digestibilidade $(92,51 \%)$ para a proteína bruta. Este coproduto, por se tratar de um xarope resultante do processo de purificação do ácido cítrico, tem a presença do ácido que possivelmente influenciou $0 \mathrm{pH}$ da ração prejudicando a digestibilidade da fração proteica.

As frações lipídicas das dietas apresentaram resultado de digestibilidade igual nos tratamentos controle, precoat $\mathrm{e}$ rafinate. Um resultado significativamente inferior para a DEE ocorreu naquela dieta com a inclusão do micélio, muito embora este resultado tenha uma indicação evidente de sua origem.

A digestibilidade da fração mineral (DMM) das dietas se mostrou igual nos tratamentos controle, micélio e precoat, diferindo estatisticamente apenas na dieta com inclusão de rafinate que apresentou resultado significativamente maior $(89,30 \%)$. Este coproduto, conforme comentado anteriormente, tem um teor de ácido cítrico 0 que provavelmente contribuiu para influenciar a taxa de 
ionização dos minerais melhorando assim sua digestibilidade e consequente maior retenção no organismo se estivesse sendo testado in vivo.

A fibra pode ser definida como sendo 0 componente estrutural das plantas (parede celular), a fração menos digestível dos alimentos, a fração do alimento que não é digerida por enzimas de mamíferos ou a fração do alimento capaz de promover a ruminação (WEISS, 1993). A taxa de digestibilidade da fibra em detergente ácido (DFDA) foi influenciada pelas inclusões dos coprodutos. A dieta controle mostrou maior DFDA, seguida pelas dietas com inclusão do micélio, precoat e rafinate. $A$ diminuição na digestibilidade da fibra pode reduzir o consumo deste nutriente quando o enchimento ruminal é o fator limitante, tal como ocorre no início da lactação (Macedo Júnior, 2007).

Comportamento semelhante a DFDA foi observado sobre a DFDN em que a dieta controle apresentou resultado superior, seguido da dieta com inclusão de precoat. Os piores resultados foram obtidos para o micélio e rafinate. Segundo Macedo Júnior (2007), a concentração de FDN na dieta está negativamente correlacionada com 0 consumo de matéria seca (CMS) em razão da fermentação mais lenta e de maior tempo de permanência no rúmen. Porém, segundo este mesmo autor, a fibra com maior digestibilidade pode estimular o consumo, pelo aumento da taxa de passagem, criando espaço para outra refeição.

Os resultados demonstram que a inclusão destes coprodutos influenciou de forma diferente a taxa de digestibilidade da MS, PB, EE, MM e FDA, mas, contudo observa-se variação muito estreita entre os tratamentos, com um coeficiente de variação de 3,$36 ; 1,61 ; 8,10 ; 3,01$ e $7,01 \%$ respectivamente. Variação maior foi observada somente para a digestibilidade da fibra detergente neutro (DFDN), o que permite inferir que a inclusão, nos níveis testados, não comprometeu a qualidade das dieferentes dietas.

\section{CONCLUSÃO}

Os coprodutos Micélio, Precoat e Rafinate originários da indústria de processamento do milho e ácido cítrico, podem ser considerados matéria prima de inclusão nas dietas de ruminantes, nos níveis testados. Resultados ainda melhores poderão ser evidenciados em teste de níveis de inclusão destes alimentos em dietas.

\section{REFERÊNCIAS BIBLIOGRÁFICAS}

AQUARONE, E.; BORZANI, W., LIMA, U.A. Biotecnologia: tópicos de microbiologia industrial. São Paulo: E. Blücher, 1990. v. 2.

BRASIL. Ministério da Agricultura e do Abastecimento. Sindicato Nacional da Indústria de

Alimentação Animal. Associação Brasileira da Indústria de Alimentação Animal. Colégio

Brasileiro de Nutrição Animal. Métodos analíticos. In: Compêndio Brasileiro de Alimentação Animal. São Paulo: Sindirações, 2009.

FERRARI, R. A., COLUSSI, F; AYUB, R.A. Caracterização de Subprodutos da Industrialização do Maracujá Aproveitamento das Sementes. Revista Brasileira de Fruticultura, Jaboticabal SP, v. 26, n. 1, p. 101-102, 2004.

GONÇALVES, M. F.; SANTOS, S. F.; VISONÁ-OLIVEIRA M.; FERNANDES, E. A.; RIOS, M. P.; FERREIRA, I. C. Farelo úmido de glúten de milho (FUGM) sob diferentes tipos de armazenagense dias de aberturas dos silos. Anais... 49a Reunião da Sociedade Brasileira de Zootecnia. Brasília, 2012.

MACEDO JUNIOR, G.L.; ZANINE, A.M.; BORGES, I.; PÉREZ, J.R.O. Qualidade da fibra para a dieta de ruminantes. Ciência Animal, v.17, n.1, p.7-17, 2007.

NOLLER, C.H.; NASCIMENTO JR., D.; QUEIROZ,D.S. Determinado as exigências nutricionais de animais em pastejo. In: SIMPÓSIO SOBRE MANEJO DE PASTAGENS, 13, 1996, Piracicaba. Anais... Piracicaba: FEALQ, 1996. p.319352. 
PELIZER, L. H.; PONTIERI M. H.; MORAES I. O. Utilização de resíduos agro-industriais em processos biotecnológicos como perspectiva de redução do impacto ambiental. Journal of Technology Management \& Innovation, v.2, n. 1, 2007.

SILVA, D.J.; QUEIROZ, A.C. Análises de alimentos (métodos químicos e biológicos). 3.ed. Viçosa, MG: Editora UFV, 2002. 235p.

TILLEY, J.M.A., TERRY, R.A. A two stagee technique for the in vitro digestion of forage crops. Joumal of the British Grassiand Society., v. 18, n. 2, p. 104111, 1963.

TIMOFIECSYK, F.R; PAWLOWSKY, U. Minimização de resíduos em indústria de alimentos. In: Boletim do Centro de Pesquisa e Processamento de Alimentos. v. 18, n.2 jul/dez p. 221-235, 2000.

WATANABE, P. H.; EZEQUIEL, J. M. B.; GALATI, R. L.; BIAGIOLI, B.; SILVA, O. G. C. Indicadores internos indigestíveis para a estimativa das digestibilidades de dietas à base de coprodutos. Revista Brasileira de Saúde e Produção Animal, v.11, n.3, p.849-857, 2010.

WEISS, W.P. Predicting energy values of feeds. Journal of Dairy Science, v.76, p.1802, 1993. 